\title{
ROADMAP
}

Check for updates

\section{Organ donation and transplantation: a multi-stakeholder call to action}

\begin{abstract}
Raymond Vanholder ${ }^{1,2} \bowtie$, Beatriz Domínguez-Gil ${ }^{3}$, Mirela Busic ${ }^{4}$, Helena Cortez-Pinto 5,6,7, Jonathan C. Craig ${ }^{8}$, Kitty J. Jager', Beatriz Mahillo3, Vianda S. Stel ${ }^{9}$, Maria O. Valentin (10) ${ }^{3}$, Carmine Zoccali ${ }^{10,11}$ and Gabriel C. Oniscu (i) ${ }^{12,13}$

Abstract $\mid$ Although overall donation and transplantation activity is higher in Europe than on other continents, differences between European countries in almost every aspect of transplantation activity (for example, in the number of transplantations, the number of people with a functioning graft, in rates of living versus deceased donation, and in the use of expanded criteria donors) suggest that there is ample room for improvement. Herein we review the policy and clinical measures that should be considered to increase access to transplantation and improve post-transplantation outcomes. This Roadmap, generated by a group of major European stakeholders collaborating within a Thematic Network, presents an outline of the challenges to increasing transplantation rates and proposes 12 key areas along with specific measures that should be considered to promote transplantation. This framework can be adopted by countries and institutions that are interested in advancing transplantation, both within and outside the European Union. Within this framework, a priority ranking of initiatives is suggested that could serve as the basis for a new European Union Action Plan on Organ Donation and Transplantation.
\end{abstract}

European Kidney Health Alliance

(EKHA). A non-governmental advocacy organization promoting the cause of kidney patients at the level of the European Union and the European Union member states.
Organ transplantation improves patient survival and quality of life and has a major beneficial impact on public health and the socio-economic burden of organ failure. In the European Union (EU), a relatively coherent and structured approach to transplantation exists, with well-developed national programmes, international schemes to facilitate organ sharing and well-defined exchange policies ${ }^{1}$, making Europe a leader in the field. Between 2009 and 2015, the EU operated a successful Action Plan to promote organ donation and transplantation ${ }^{2}$. However, transplantation rates today differ markedly between EU countries, suggesting that there remains room for improvement. To address the differences, the European Commission convened a Thematic Network coordinated by the European Kidney Health Alliance (EKHA), tasked with providing guidance to increase organ donation and transplantation and presenting key action points that would increase the prevalence of patients living with a functioning transplant throughout Europe. This thematic network culminated in the publication of a joint statement that recommends strategies to promote transplantation and donation in the EU and, by extension, throughout Europe ${ }^{3}$. Although the focus of this statement is on adult and paediatric transplantation of solid organs, many recommendations are also applicable to tissue transplantation (for example, cornea).
This Roadmap summarizes and builds on the Joint Statement and the experience gained from implementation of the earlier Action Plan to recommend strategies through which transplantation activities and the number of individuals living with a functioning transplant in Europe can be enhanced. We outline the challenges posed by the development and implementation of a EU-wide transplantation strategy and propose 12 key areas in which specific measures should be considered to promote transplantation, providing an overall framework that can be adopted by countries and institutions to improve rates of donation and transplantation (FIG. 1). These areas were selected and defined by a group of experts, including members of professional organizations, and authorities from national health-care bodies. As the Joint Statement is a product of a European Commission initiative, most of the recommendations herein are aimed at improving the current status of transplantation within the EU, but importantly these recommendations are also relevant to the $17 \mathrm{EU}$-associated countries and to regions elsewhere in the world, with some adaptations to local conditions if required.

\section{Current status of transplantation in Europe}

Non-communicable (chronic) diseases (NCDs) impose a substantial burden on health-care systems, economies, quality of life, employment status and social activities. 


\section{Key points}

- Differences in the frequency of transplantation between countries in the European Union suggest that there is room for improvement, wherein countries with low transplantation rates could learn from the experience of countries that are doing well.

- Efforts to increase transplantation rates require a variety of strategies, including approaches to increasing living and deceased donation, improving coordination of the donation and intensive care unit processes, increasing graft quality and optimizing expanded donation criteria.

- Education should cover the complete spectrum of society (the general population, patients and medical professionals) with specific outreach methods to under-represented communities and individuals who are health illiterate.

- Infrastructural and financial barriers to transplantation should be banned.

In Europe, NCDs are responsible for $77 \%$ of the disease burden and $86 \%$ of deaths ${ }^{4}$, many of which are in young individuals ${ }^{5}$. Changes in population demographics and the growing prevalence of risk factors have contributed to an increase in the demand for organ replacement therapies. Artificial organ support is an option in some instances, but is only available on a large scale for kidney failure in the form of dialysis. Hence, transplantation is for many patients the only solution to restoring organ function and preventing premature death. The WHO has urged countries to progress towards self-sufficiency in transplantation, first by preventing NCDs and their progression to end-stage organ failure, but also through the provision of sufficient numbers of life-saving transplants to match their need ${ }^{6,7}$. The WHO further emphasizes that deceased donation should be developed to its maximum therapeutic potential.

More than 34,285 solid organ transplantations were performed in the EU in $2019,85 \%$ of which were kidney $(21,235)$ and liver $(7,900)$ transplants. Cardiothoracic transplantation represented $13 \%$ of activity with 2,269 hearts and 2,136 lungs transplanted, whereas pancreas (2\%), small bowel and multi-visceral transplants represented only a small fraction (TABLE 1; FIG. 2). Although the total number of annual transplantations rose by 4,540 between 2010 and 2017, the number of annual transplantations from 2017 to 2019 increased by only 161,

\footnotetext{
Author addresses

${ }^{1}$ Department of Internal Medicine and Paediatrics, Ghent University Hospital, Ghent, Belgium.

'European Kidney Health Alliance (EKHA), Brussels, Belgium.

${ }^{3}$ Organización Nacional de Trasplantes (ONT), Madrid, Spain.

${ }^{4}$ Ministry of Health, Zagreb, Croatia.

${ }^{5}$ Clínica Universitária de Gastrenterologia, Faculdade de Medicina, Universidade de

Lisboa, Lisboa, Portugal.

${ }^{6}$ United European Gastroenterology (UEG), Vienna, Austria.

'European Association for the Study of the Liver (EASL), Geneva, Switzerland.

${ }^{8}$ College of Medicine and Public Health, Flinders University, Adelaide, Australia.

${ }^{9}$ ERA-EDTA Registry, Department of Medical Informatics, Amsterdam Public Health

Research Institute, Amsterdam UMC, University of Amsterdam, Amsterdam, The

Netherlands.

${ }^{10}$ Associazione Ipertensione Nefrologia e Trapianto Renale (IPNET), Reggio di Calabria, Italy.

${ }^{11}$ European Renal Association - European Dialysis and Transplant Association (ERA-EDTA), London, UK.

${ }^{12}$ Edinburgh Transplant Centre, Royal Infirmary of Edinburgh \& University of Edinburgh, Edinburgh, UK.

${ }^{13}$ European Society of Organ Transplantation (ESOT), Amsterdam, the Netherlands.
}

indicative of a stagnation in transplantation activity, possibly related to the end of the EU Action Plan in 2015 (FIG. 2).

Transplantation of organs from deceased donors remains the most prevalent form of transplantation throughout the EU. Although deceased donor transplantation occurs most frequently from donors declared dead by neurological criteria (donation after brain death; DBD), donation after death declared by circulatory criteria (donation after circulatory death; DCD) contributes to transplant activity in a number of countries ${ }^{8}$ (TABLE 2; FIG. 3). However, substantial variability exists in the use of DCD transplantation between EU member states. DCD is not permitted in a number of European countries because of legislative and ethical obstacles ${ }^{9,10}$, and practiced in only a few cases in many other countries ${ }^{8}$. In 2019, 28 of 35 European countries had an active DCD programme compared with just 10 in $2011\left(\right.$ REF. $\left.^{10}\right)$, but in several of these countries the DCD activity was marginal (FIG. 3). In 2019, DCD contributed to $17.8 \%$ of deceased donation transplantations in the EU. Living donation (almost exclusively kidney and liver), which is particularly beneficial to paediatric recipients, represents a considerable proportion of transplant activity in some but not all European countries ${ }^{8}$ (TABLES 1,2; FICS 3,4).

The number of organ transplant procedures for the EU as a whole was 67.2 per million population in 2019, with marked differences between countries ${ }^{8,11}$ (FIG. 3), reflecting differences in local health-care processes, efforts to develop living and deceased organ donation, available infrastructure and expertise, and economic factors $^{12}$. Most EU member states have seen an upward trend in transplantation rates over the past decade, but some countries have seen a substantial decrease (FIG. 4). These decreases are in some cases influenced by external factors, such as public mistrust ${ }^{13}$, and have negative consequences on patient outcomes ${ }^{8,11}$.

For most vital organs (liver, heart, lungs), transplantation is the only life-saving therapy. For patients with kidney failure (also known as end-stage kidney disease), which is rapidly rising in the ranked order of fatal diseases ${ }^{14}$, kidney transplantation offers not only a better survival and quality of life than dialysis ${ }^{15-17}$, but can be life-saving when vascular access options are lost. Yet, by the end of 2019, more than 58,000 patients were waiting for an organ transplant in the EU (FIG. 5). Yearly, 3-4\% of those on the waiting list die before being transplanted, representing 10-11 patient deaths daily. This figure is probably an underestimate, owing to incomplete data reporting in some countries. The mismatch between the need for transplants and donor supply, which excludes patients from lifesaving treatment, is exacerbated by the rising prevalence of health problems, such as diabetes mellitus and obesity, which reduces the donor pool; the presence of major public health challenges, such as the current COVID-19 pandemic; and improvements in critical care processes or car safety, which prevent deaths but also reduce the pool of deceased organ donors. The problems associated with access to donor organs are further illustrated by the small proportion of patients who receive a pre-emptive kidney transplant, which in most countries represents $<10 \%$ of patients starting kidney 
replacement therapy ${ }^{18}$, necessitating a variable period on dialysis with a negative impact on survival and high associated costs ${ }^{19}$.

Of note, NCDs also present a considerable health economic burden through a life-long need for consultations, medication, surgery, imaging, interventions and hospitalization. It is difficult to quantify the economic impact of organ transplantation in the absence of large-scale artificial organ treatment as an alternative option. However, for kidney failure, for which dialysis consumes at least $2 \%$ of health expenditure for only $0.1-0.2 \%$ of the general population ${ }^{1}$, transplantation is by far the most cost-effective kidney replacement option, particularly from the second year post-transplantation ${ }^{20,21}$. Economic evaluations for other solid organ transplants are less straightforward. Costs associated with liver transplantation can be substantial, particularly in the context of biliary complications that can increase the duration of hospitalization and the need for diagnostic studies and further therapeutics ${ }^{22}$. Nevertheless, liver transplantation has been reported to be cost effective ${ }^{23}$ in comparison with the rapidly

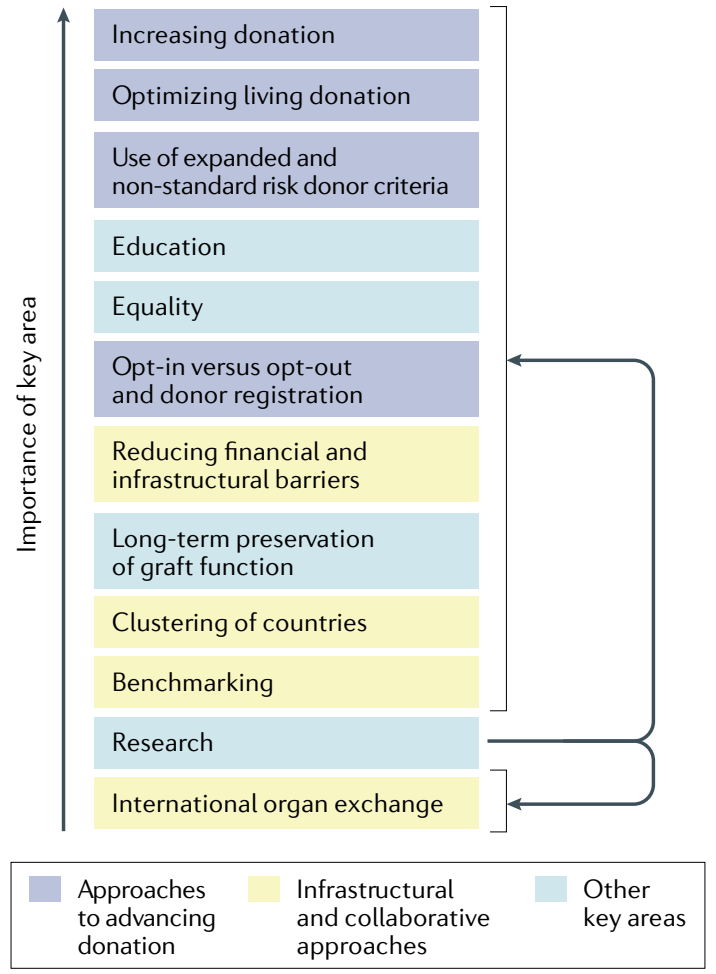

Fig. 1 Key areas in which specific measures should be considered to promote transplantation. These topics have been ranked in order of priority; however, this ranking should be considered with caution as it represents a subjective judgement by the authors of this Roadmap, possibly biased by confounding factors such as region of residence, precise involvement and responsibility in transplantation activity, personal opinion and extent of solid evidence base. Furthermore, given the variations discussed in the Roadmap, the ranking of these topics may vary between different countries or stakeholders. In addition, the topics are highly interdependent (as illustrated by colour coding) and cannot be considered in isolation. Research is linked to all topics. rising costs of non-transplanted liver disease (including costs of medication, radiological procedures, and repeated and prolonged hospital admissions $)^{24}$. Heart failure is a leading cause of morbidity and mortality worldwide and places a huge burden on health-care systems; available data suggest that heart transplantation is also cost-effective in eligible adult and paediatric recipient ${ }^{25,26}$.

Unemployment among patients with chronic NCDs generates pressure not only on social security but also on productivity and buying power ${ }^{27}$. Transplantation can interrupt this vicious circle, although pro-active mechanisms are needed to promote socio-economic (re)integration of individuals following transplantation, as $40-80 \%$ of transplanted patients remain unemployed or permanently disabled ${ }^{28-30}$.

Finally, patients with NCDs also experience a heavy burden of polypharmacy, diet restrictions, comorbidities, and time spent in hospital and travelling to medical appointments. Transplantation restores not only organ function but also quality of life $\mathrm{e}^{20,31}$. For children, transplantation also leads to improvement in development, growth, education and mental health in the recipient and in quality of life for the carer ${ }^{32}$.

The benefits of transplantation prompted the EU to launch the Action Plan on Organ Donation and Transplantation, which aimed to increase organ availability, enhance efficiency and accessibility of transplant procedures, and improve the quality and safety of organs intended for transplantation. It was implemented from 2009 to $2015\left(\mathrm{REFS}^{2,33}\right)$. At the end of 2019 , a $16 \%$ overall increase in transplantation rate was observed compared with $2010^{8}$ (TABLE 1 and FIG. 2). This increase varied for different types of transplants (for example, $42 \%$ increase for lung transplantation, $17 \%$ for liver and $15 \%$ for kidney transplantation) and was primarily a result of a substantial increase in $\mathrm{DCD}^{8}$, suggesting that $\mathrm{DBD}$ and living donation may also benefit from further stimulatory interventions. Moreover, the initial rise in transplantation rate observed after 2012 seems to have somewhat levelled off in the past few years (FIG. 2), suggesting that the effect of the EU Action Plan has lost some momentum and that a new plan may be needed.

Data specific to kidney transplantation show that implementation of the Action Plan was associated with a rise in the total number of kidney transplantations and in the percentage of patients living with a functioning kidney graft in the EU (Supplementary Table 1). However, marked differences between countries are evident, underscoring the need for further action to boost transplantation rates in some regions.

\section{Topics for action}

Variations in transplantation practices and policies between European countries have led to differences in access to transplantation; in some instances, patients who may benefit from transplantation are not considered eligible (for example, owing to age or the presence of comorbidities or mental health issues) ${ }^{34}$. The optimal approach to increasing transplantation rates is to set well defined, ambitious goals, such as an aggregated increase in the number of EU transplantations by $10 \%$ in 10 years, complemented by specific development plans that detail 
Table 1 | Organ transplantation activity in the EU from 2009 to 2019

\begin{tabular}{|llll|}
\hline & $\begin{array}{l}\text { Number of } \\
\text { transplantations } \\
\text { in 2010 (PMP) }\end{array}$ & $\begin{array}{l}\text { Number of } \\
\text { transplantations } \\
\text { in 2019 (PMP) }\end{array}$ & $\begin{array}{l}\text { \% change } \\
\text { (PMP) }\end{array}$ \\
\hline Kidney & $18,490(36.8)$ & $21,235(41.6)$ & +14.8 \\
\hline Liver & $6,767(13.5)$ & $7,900(15.5)$ & +16.7 \\
\hline Heart & $2,020(4.0)$ & $2,269(4.4)$ & +12.3 \\
\hline Lung & $1,505(3.0)$ & $2,136(4.2)$ & +41.9 \\
\hline Pancreas & $752(1.5)$ & $710(1.4)$ & -5.6 \\
\hline Small bowel & $50(0.1)$ & $35(0.1)$ & -30.0 \\
\hline TOTAL & $\mathbf{2 9 , 5 8 4 ( 5 8 . 9 )}$ & $\mathbf{3 4 , 2 8 5 ( 6 7 . 2 )}$ & $+\mathbf{1 5 . 9}$ \\
\hline
\end{tabular}

Transplantation activity data for the EU in 2010 (including data for Croatia, which was not at the time part of the EU) and 2019. Data were calculated based on the databases that are used for the production of the Transplant Newsletter ${ }^{135}$. PMP, per million population.

the elements required to support individual countries or groups of countries according to the local conditions. This strategy should be followed by an implementation plan at a national level with internal and external auditing. Several organizations, such as the Council of Europe, have previously formulated recommendations and resolutions to increase transplantation at the institutional level (summarized in Supplementary Table 2). This Roadmap is complementary to those efforts and extends these initiatives by outlining a comprehensive multinational policy approach ${ }^{33,35,36}$. Barriers to transplantation ${ }^{37,38}$, which are often psychological and practical in nature, may be avoided through appropriate education and regulation ${ }^{2}$ (BOX 1).

Lessons can also be learned from countries that are performing well. For example, measures taken by Spain to increase rates of deceased organ donation ${ }^{39-41}$ over recent decades have had remarkable success ${ }^{8}$ (Supplementary Figure 1). These measures have included a strong emphasis on coordinating the donor process, use of a pyramidal structure to coordinate processes from local to regional and national offices, engagement of the critical care community, benchmarking, provision of guidance and continuous professional training, and the increased use of living donation, expanded donor criteria and DCD organs ${ }^{39-41}$. Regions such as Croatia, Northern Italy, the UK and France, which adapted the Spanish model to their local circumstances, also saw an increase in transplantation rates ${ }^{42}$, enabling these regions to focus on equality of access and approaches to optimizing outcomes and education. Other countries, such as the Netherlands, have also increased their transplantation rates substantially, largely through increasing rates of living donation (Supplementary Table 1).

Herein we summarize 12 key domains that informed the Joint Statement commissioned by the European Commission $^{3}$ and in which action could enable further increases in the number of donations, transplantations and patients living with a functioning transplant. These topics form the basis of a Roadmap that is intended for use by the EU, EU health-care authorities, patient associations and professional societies to guide the implementation of measures to stimulate organ donation and transplantation. Beyond increasing rates of organ donation and transplantation, the involved communities should do their utmost to maximize the longevity of transplanted organs, which is an absolute priority for the recipients ${ }^{43,44}$. To guide implementation of strategies that address each of these areas, we have ranked the 12 key topics in order of importance (FIG. 1). Of note, however: this ranking should be considered with caution given that it is largely opinion based, given the variation in the extent to which each of these areas may need to be addressed differently in different countries, and the interdependent nature of the areas, such that they can only be considered and implemented together. The highly integrated nature of these areas renders it near impossible to disaggregate and quantify the potential impact of individual interventions within a topic. However, all examples provided within this Roadmap refer to countries with a high transplantation rate ( $>60$ per million population per year).

\section{Increasing donation}

Increasing the number and quality of donated organs is a key element in increasing donation rates. Several strategies exist to facilitate this donation process.

Maximizing the role of donor coordinators. Proper coordination of the donation process is a key element in increasing donations and optimizing outcomes. The European models that have been most successful centre around the involvement of efficient donor coordinators, who are independent of the transplantation team, and are based in each hospital that has potential for deceased donation. These coordinators have key roles in the steps leading to the traditional model of deceased donation - a process that involves potential donor selection, maintenance of the haemodynamic status of the donor and organ perfusion, diagnosis of death and communication with the family. These individuals are trained in recognizing donation opportunities in end-of-life care pathways and in providing grieving families with the psychological support required to make the often difficult decision to agree to donation. Critical to the overall success of these programmes has been the appointment of professionals who develop a proactive programme for the identification of possible donors, in close cooperation with the critical care community. Donor coordinators should receive continuous training, with special attention given to the skills required to communicate with grieving relatives and organize organ handling with minimal delay. Local networks should be supported by national and regional cells that focus more on policy and technical aspects ${ }^{39}$. Regular internal and external audits should be used to identify areas for improvement ${ }^{39}$.

Optimizing the role of intensive care professionals. Engagement with intensive care professionals is particularly important to ensure that deceased donation is always considered as an option for patients receiving end-of-life care, provided that it is appropriate and consistent with the potential donor's wishes and values ${ }^{45,46}$. Optimizing the role of intensive care professionals in the donation process requires a number of steps, including the identification of intensivists who will champion donation in their unit and in their hospital or region as 
Pre-emptive transplantation A situation in which a kidney transplant candidate receives a donor kidney before starting on dialysis.

Organ-sharing schemes Programmes that enable sharing of organs between donor-recipient pairs who cannot exchange a donor organ directly with each other.

\section{Minimizing the duration of the donation process. The time between consideration of donation opportuni- ties and initiation of the actual donation procedure can vary considerably and can exceed $24 \mathrm{~h}$ sometimes substantially ${ }^{47}$. Hesitation in donor identification and donor handling by medical staff as well as indecision of families owing to socio-cultural, religious or educational barriers ${ }^{48}$ all affect the duration of the donation process, as do organizational factors such as the length of the pro- cess before an organ is offered to a potential recipient, the need for additional tests and lack of timely access to surgical theatres. These delays may have adverse effects on donation by increasing the risk of donor organ dete- rioration or withdrawal of family consent, leading to the loss of otherwise transplantable organs. Therefore, national programmes should focus on approaches to facilitating the identification of all possible donors, the early notification of donor coordinators and work with}

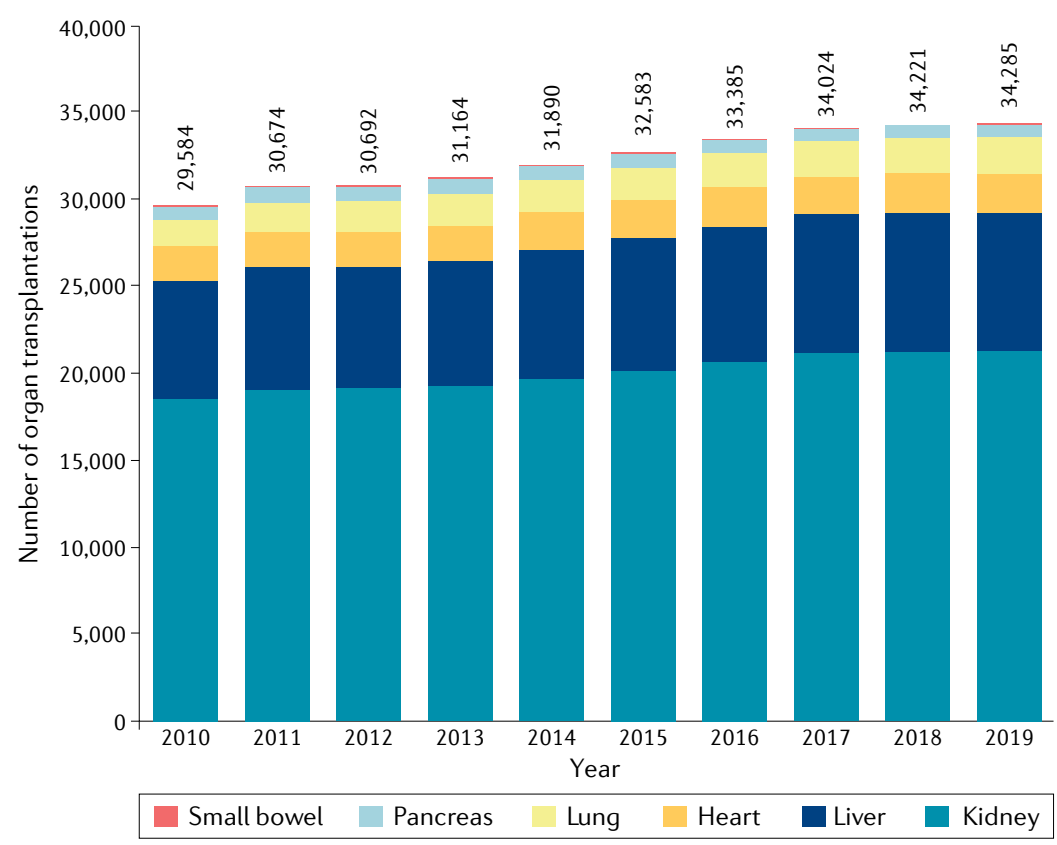

Fig. 2 | Number of organ transplantations performed in the EU between 2010 and 2019. As Croatia was not part of the EU in 2010-2011, the data for transplantations performed in Croatia were added to the data for the $27 \mathrm{EU}$ member states for those years. The absolute total number of transplantations for each year is provided. The corresponding number per million population increased from 59 (2010) to 67 (2019). The EU Action Plan on Organ Donation and Transplantation was operational between 2009 and 2015. The marked rise in yearly transplantation rate observed particularly in the last years of the EU Action Plan on Organ Donation and Transplantation (2012-2015) seems to have levelled off in the years 2016-2019. Data were calculated based on data from the Transplant Newsletter ${ }^{135}$. families to reduce the rate of donation refusal ${ }^{49}$, thus avoiding donor loss.

\section{Optimizing living donation}

Transplantation of a kidney from a living donor offers markedly better chances for graft and patient survival than transplantation of a kidney from a deceased donor $^{50}$, whereas living donor liver transplantation involves a similar hospital stay and survival rates to deceased donor transplantation ${ }^{51}$. Although practiced in almost every EU country, living donation has a variable contribution to overall transplantation activity. It is markedly low in many countries, even in those with well-established transplantation programmes, with the Netherlands and Iceland as notable exceptions (FICS 3,4, Supplementary Table 1). Living donation remains the method of choice for infants and children, in particular for those with kidney failure, because it enables pre-emptive transplantation and avoids the need for dialysis. In the Netherlands, kidney transplantation is largely driven by living donation, making it a country with one of the highest proportion of patients on kidney replacement therapy living with a functioning transplant in the EU (Supplementary Table 1).

Donor safety remains paramount and should be the primary focus of any living donation programme. However, it is equally important to demystify the risks of living donation, through a uniform process of information (for both the donor and recipient) and evaluation (via an online approach if convenient) to ensure that all essential information is conveyed and understood ${ }^{52}$ (see below and Supplementary Box 1). This approach will encourage expansion of living donation programmes, increasing access to transplants for patients from ethnic minorities and economically challenged backgrounds who are often disadvantaged overall in transplantation programmes (see below). Living kidney donors may have a low but increased risk of developing hypertension ${ }^{53}$ or kidney failure ${ }^{54}$, and therefore robust living donor programmes should carefully select donors, include an adequate follow-up, and if needed, preventive treatment. Moreover, and in contrast to the experience of many organ donors ${ }^{55}$, the donation process should be financially neutral. Processes therefore need to be in place to ensure that living donors do not face out-of-pocket costs and lost wages, or difficulty securing health or life insurance ${ }^{56}$.

Approaches to broadening donor and recipient criteria, including the involvement of emotionally related and unrelated altruistic donors and organ-sharing schemes, enable the expansion of living donation programmes. Although sharing schemes exist in a number of EU countries such as in the Netherlands and Spain, they remain non-existent or very limited in others ${ }^{8,57,58}$. Of note, a number of European and cross-border organ-sharing initiatives have been implemented to redress this situation ${ }^{59,60}$.

The implementation of initiatives to encourage living donation raises organizational and ethical questions, which have been addressed in a reference toolkit developed by the European Commission and National Agencies $^{61}$. Any common ethical framework for 
Table 2 | Organ donation activity in the EU from 2009 to 2019

\begin{tabular}{|llll} 
& $\mathbf{2 0 1 0} \mathbf{N}(\mathbf{P M P})$ & $\mathbf{2 0 1 9} \mathbf{N}$ (PMP) & \% change (PMP) \\
\hline DBD & $8,626(17.2)$ & $9,443(18.5)$ & +9.5 \\
\hline DCD & $715(1.4)$ & $2,049(4.0)$ & +186.6 \\
\hline Actual DD & $9,341(18.6)$ & $11,492(22.5)$ & +23.0 \\
\hline LD & $3,879(7.7)$ & $4,259(8.3)$ & +9.8 \\
\hline TOTAL DONATIONS & $\mathbf{1 3 , 2 2 0 ( 2 6 . 3 )}$ & $\mathbf{1 5 , 7 5 1 ( 3 0 . 8 )}$ & $\mathbf{+ 1 9 . 1}$
\end{tabular}

Organ donation activity data for the EU in 2010 (including data for Croatia, which was not at the time part of the EU) and 2019. Data were calculated based on data from the Transplant Newsletter ${ }^{135}$. DBD, donation after brain death; DCD, donation after circulatory death; $\mathrm{DD}$, deceased donations; LD, living donations.

unrelated living donation should be regulated at an EU level to alleviate any concern that pressure may be exerted on the candidate donor to benefit an irreversibly sick person and alleviate the associated societal costs ${ }^{62}$.

\section{Use of expanded donor criteria}

The term 'expanded criteria donor' is commonly applied to donors whose clinical-demographic characteristics would have an impact on the quality of the organ and its expected longevity. The traditional definition of an expanded criteria kidney donor includes age $>60$ years or age $>50$ years with at least two of the following: a history of hypertension, serum creatinine level $>1.5 \mathrm{mg} / \mathrm{dl}$ $(132.6 \mu \mathrm{mol} / \mathrm{l})$ or death from cerebrovascular accident ${ }^{63}$. However, this dichotomous definition has increasingly been replaced by risk scores to guide the categorization and use of all organs (liver, kidney, pancreas) ${ }^{64-66}$. The increased use of expanded criteria donor organs and the changing profile of the potential donor pool has led to the increased use of organs from donors with a high comorbidity burden (for example, donors with diabetes mellitus). For patients with kidney failure, these organs can improve survival compared with remaining on dialysis $^{67}$. Dual kidney transplantation (whereby both kidneys from a donor are transplanted into a recipient) can also allow the use of organs from marginal (for example, older) donor ${ }^{68}$.

DCD organs have in the past been considered to yield inferior post-transplant results compared with those achieved with DBD donor organs. However, increased experience has led to the attainment of appropriate post-transplantation outcomes with DCD organs ${ }^{69,70}$. Efforts can be required to overcome the legal and ethical barriers to DCD transplantation, such as the absence of a legal framework regulating the cessation of therapy, and to increase the confidence of transplantation professionals in the outcomes obtained with the use of DCD organs. Advances in organ perfusion protocols may be required to better preserve DCD organ quality and prevent the unnecessary discarding of suitable organs ${ }^{71-73}$; however, the role of in situ and ex situ preservation strategies and the type of organs that require these interventions require further study ${ }^{73}$.

Non-standard risk donors are defined as those with specific conditions or diseases (for example, infections or malignancies) that can potentially affect the safety of the transplant recipient. Transplantation of these organs can be appropriate provided that an individualized risk-assessment is performed and that recipients are properly selected ${ }^{74}$. Examples of this scenario include the use of organs with unusual anatomy but appropriate functionality (Supplementary Box 2), transplantation of $\mathrm{HIV}$-infected grafts into recipients with $\mathrm{HIV}^{75}$, or transplantation of hepatitis $\mathrm{C}$ virus (HCV)-infected grafts into $\mathrm{HCV}$-negative recipients - a process that is now possible with the use of direct-acting antiviral agents ${ }^{73,76}$. For heart transplantation alone, full use of all available organs from HCV-positive donors would increase the transplantation rate by about $3 \%{ }^{77}$. Thus, the combined use of all available donor expansion measures could increase transplantation rates substantially.

EU countries that provide a legal framework for euthanasia are the Netherlands, Luxembourg, Belgium and as of June 2021, Spain. Organ donation after euthanasia in those countries is medically possible and thus represents a further option to provide these patients with the opportunity of organ donation and to expand the donor pool ${ }^{78,79}$.

Despite satisfactory outcomes ${ }^{10,69,70}$, many expanded and non-standard criteria donor organs remain underused in European countries ${ }^{8,10,80,81}$. An analysis from the USA demonstrated that the transplanted counterparts of $>15 \%$ of unilaterally discarded donor kidneys showed a death-censored 5 -year survival $>85 \%^{82}$. Thus, discarded organs have the potential to contribute substantially to the donor organ pool and their use should be supported through the provision of information to health professionals about the benefit of using them and to the potential recipient, highlighting the benefits and risks of alternative choices. The rate of organ discard in Europe might be reduced by the application of risk score systems to guide the identification of suitable organs and appropriate recipients ${ }^{83}$.

\section{Education}

Several countries have implemented educational tools to promote organ donation and transplantation (Supplementary Box 1). A more harmonized approach across the EU could result in further structural improvements.

Improving communication skills of health-care professionals. Communication training should in particular focus on professionals involved in the early stages of the deceased donation process - such as emergency and intensive care physicians and donor coordinator ${ }^{45,84}$. Communication training should cover both sides of the donation and transplantation process; donor coordinators and professionals in intensive care should be trained in approaches to communicating with the families of possible donors, whereas transplantation professionals should be trained in approaches to communicating with potential recipients in an informative and efficient way. Information on the benefits and practical aspects of transplantation should be embedded in the curricula of all health practitioners, from medical students to postgraduate teaching of specialists and general practitioners (Supplementary Box 1). Specific involvement of health-care professionals trained in patient education as part of the treating team is extremely helpful. 
Education of the public. Insufficient public awareness of organ donation and transplantation ${ }^{85,86}$, including the concept of brain death ${ }^{87}$, necessitates continuous education. A highly efficient strategy involves use of mass and social media, and requires the building of active partnerships with journalists ${ }^{41}$. Education activities in schools and use of flyers or web-based tools may help to increase awareness. In Croatia, information pamphlets with answers to frequently asked questions are made available to the public, whereas in Finland, an online educational tool is provided to educate patients and the general public about kidney transplantation (Supplementary Box 1). The EKHA "Gift of life" campaign ${ }^{88}$ offers advice to policy makers and citizens on approaches to promoting organ donation. This campaign stresses the need for a coordinated European approach based on appropriate legal and structural frameworks to allow individuals and professional nephrology and patient societies to promote kidney transplantation at the national policy level in an equitable way throughout Europe with respect to the local cultural background ${ }^{88}$. Such initiatives that focus on organ donation as a whole would further public education about the benefits and processes of transplantation.

Additional barriers that exist in economically or socially disadvantaged groups, including those with a low level of educational attainment, refugees, migrants and under-represented communities, should be specifically addressed with the help of patients, patient organizations, and minority communities, to understand attitudes and develop strategies and ensure equitable access to transplantation (see later ${ }^{39}$. This aspect is particularly important as patients from these groups are generally over-represented on the transplant waiting list and under-represented in the donor population. Limited willingness to donate exacerbates the challenge of finding suitable HLA matches for kidney transplant candidates, prolonging the wait-list time, increasing the risk of mismatch, and jeopardizing long-term outcomes ${ }^{89}$.

Patient education and information. Limited health literacy (discussed below) and patient disinformation also deter transplantation ${ }^{90}$. The information provided by physicians and nurses to candidate organ recipients should discuss all treatment options, especially for kidney transplant candidates, for whom dialysis is a readily available but in many cases a less desirable alternative. Information about deceased and living donation ${ }^{2}$ should be provided, as often no information is offered about the two options (Supplementary Table 3). Education about organ replacement options should be provided as patients approach organ failure and be delivered in a tailored way either in hospital, in outpatient clinics or at home (Supplementary Box 1). Patient records should include an explicit statement on the suitability of the patient for transplantation, including the views of the patient and, particularly in the case of living donation,

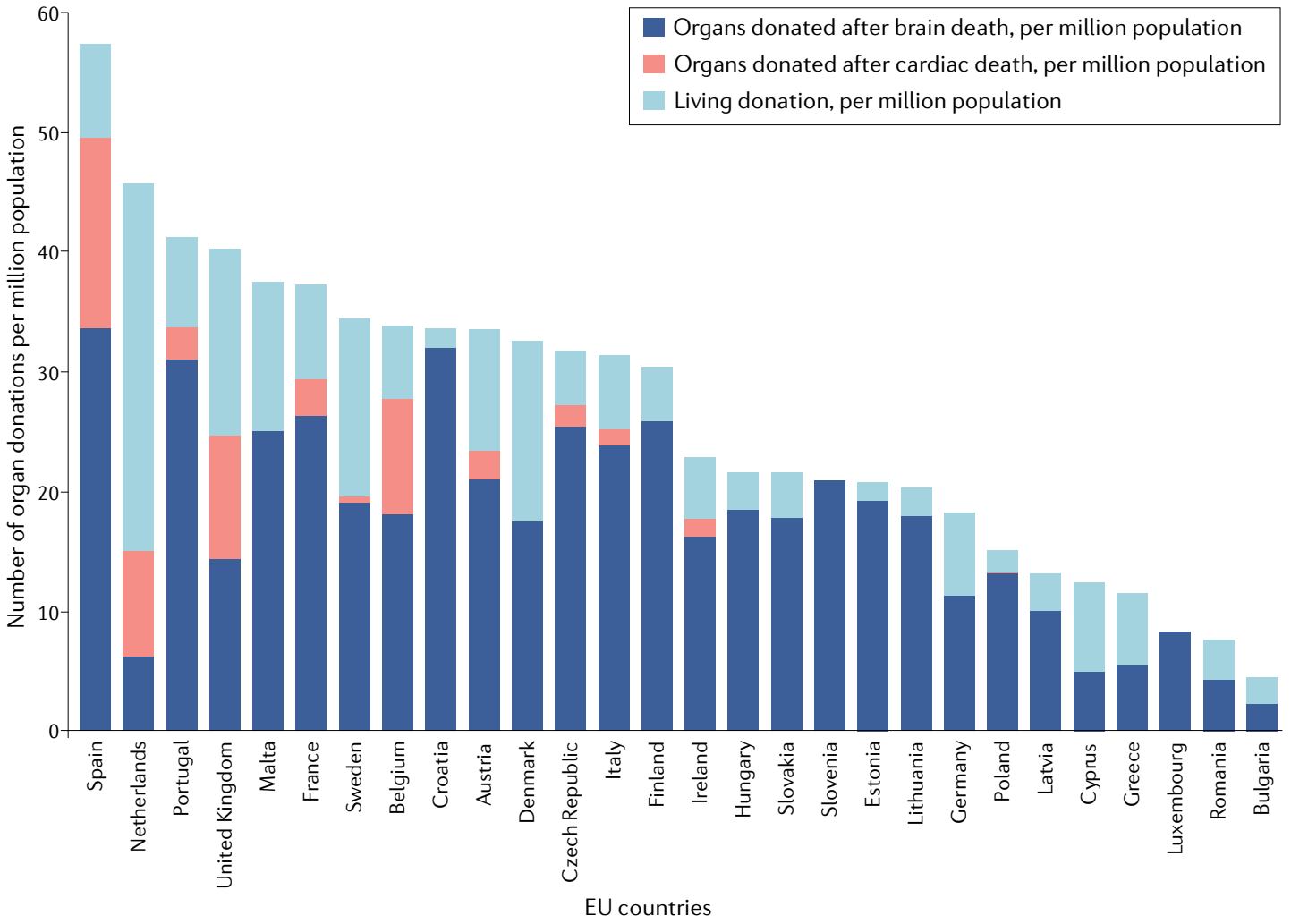

Fig. 3 | Number of organ donations per million population in 2019. Substantial differences exist between EU countries in terms of their overall rates of donation but also in terms of the specific types of donation. Only 11 of the 28 countries (39\%) use notable quantities of organs donated after cardiac death. Although all EU countries perform transplantation after living donation, substantial differences in the rates of living donor transplantation exist between countries. Data were calculated based on data from the Transplant Newsletter ${ }^{135}$. 


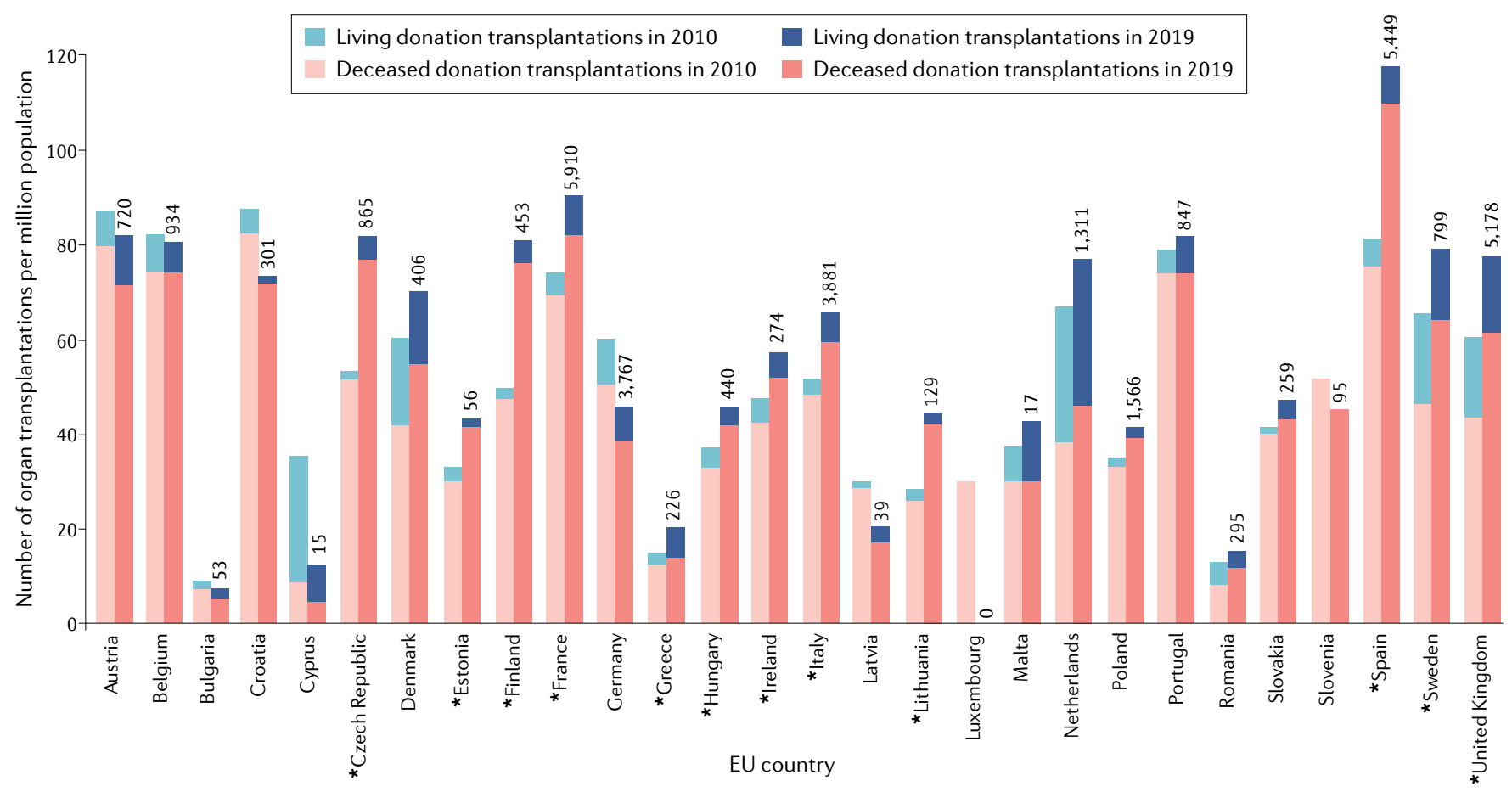

Fig. 4 | Number of organ transplantations per million population in 2010 and 2019. Of 28 countries, 12 (43\%) showed an increase in transplantation activity of $>20 \%$ (asterisks). Although most countries tended to increase or stagnate their rates of transplantation, a few show a decrease. Also shown are the absolute numbers of transplants (from deceased plus living donors) in 2019. Data were calculated based on data from the Transplant Newsletter ${ }^{135}$.

the views of their next of kin. To improve long-term patient outcomes $^{91,92}$, education should include lifestyle advice, particularly approaches to addressing excess weight, smoking, excessive alcohol intake and hypertension and to promoting a healthy diet and exercise.

In 2017, EKHA distributed a questionnaire to determine the satisfaction level of patients from six EU countries with the information that had been provided to them about the different types of kidney replacement therapy in the period preceding the start of those therapies ${ }^{2}$ (Supplementary Table 3). Patient dissatisfaction with the quality of information provided about transplantation ranged from $11 \%$ (the Netherlands) to $45 \%$ (Greece). These data confirmed findings from a previous analysis ${ }^{93}$ of data collected from 2010 to 2011, suggesting little change since then, and underscoring the need for streamlined European education for all transplant candidates. A centralized quality check on information delivery and patient satisfaction might encourage excellence. Not surprisingly, dissatisfaction about the information provided coincides with low application of a given practice, suggesting a self-fulfilling circle (for example, in the Netherlands, which has a high transplantation rate, patient satisfaction is also very high; however, proportionally more patients received only information on living donation, which very likely occurred because that is the preferred mode of donation in that country).

\section{Equality}

Achieving equality in transplantation requires that all suitable candidates - irrespective of their ethnicity, race, sex, education, socio-economic status, religion, health literacy, or language barriers - have an equal probability of receiving a transplant. However, inequalities are rife in medical practice ${ }^{94}$ and deserve specific attention. Approaches to removing barriers to transplantation can in many instances be adapted to the specific needs of minority patient groups, as exemplified by the implementation of measures to increase access to transplantation for Jehovah's Witnesses in Croatia (Supplementary Box 3). However, despite the existence of legal frameworks designed to prevent discrimination and ensure equitable access to health care and transplantation, in practice, access to transplantation remains extremely problematic for certain populations, especially for minority groups and immigrants, including undocumented migrants. These individuals face considerable barriers in access to health care, in particular to chronic therapies, including transplantation services. These barriers can arise from willing or unwilling institutional discrimination, the bias and prejudices of health professionals, as well as from non-familiarity of migrants with the medical model of the host country ${ }^{94,95}$. Educational approaches developed for the general public may not be appropriate for these communities, and specific efforts are required to ensure that these approaches reach affected individuals and are developed with input from the relevant populations. Comorbidities, such as diabetes, can be more prevalent in some ethnic minority populations, and negatively affect donation and transplantation rates ${ }^{96}$. Inequities among migrant populations are also closely linked to socio-economic status, exemplified by the well-documented associations between socio-economic status, waitlist placement and receipt of a transplant ${ }^{97}$. 
Inactive waitlisting

A category of patients on the transplant waitlist who are temporarily ineligible for transplantation because of medical, social or personal reasons.

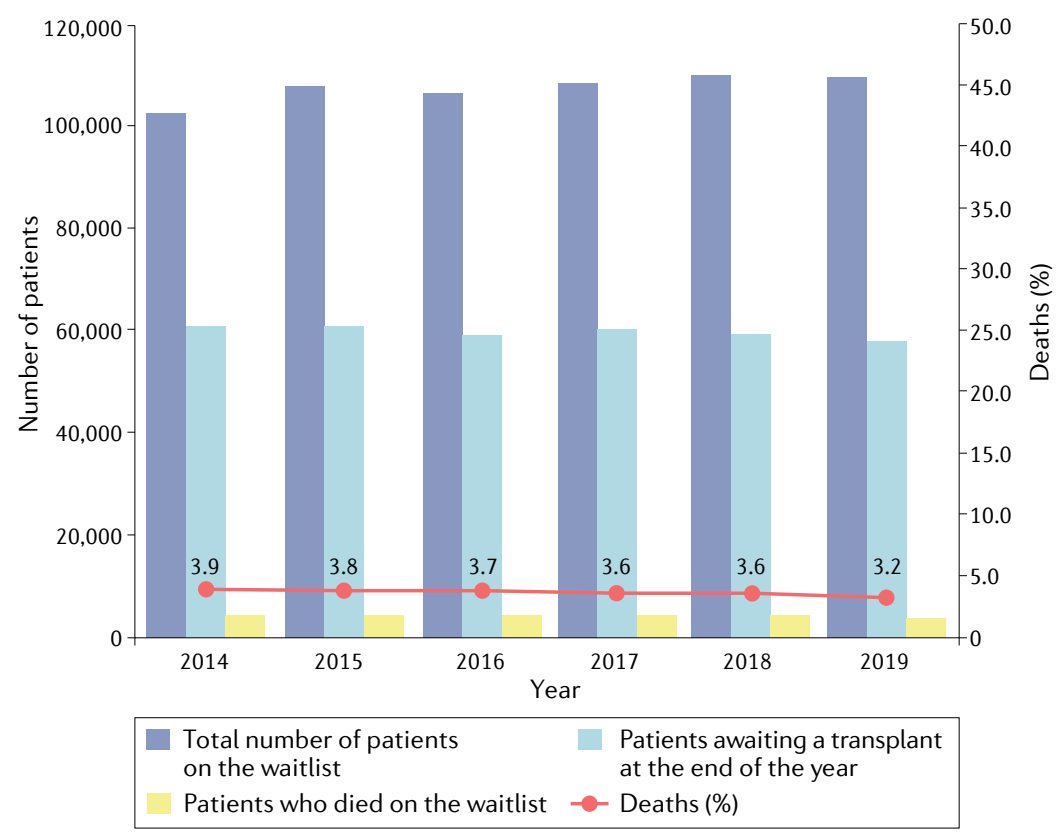

Fig. 5 | Number of waitlisted patients and patients dying on the waiting list in the EU from 2014 to 2019. The percentage of deaths (red line) is calculated as the ratio of those who died that year while waitlisted to the total number active on the waiting list that year multiplied by 100 . There was a $7 \%$ increase in the number waitlisted over this 5 -year period. The percentage of deaths remained relatively stable between 3-4\%. Data were calculated based on data from the Transplant Newsletter ${ }^{135}$.
Although tissue matching is less important a determinant for liver or cardiothoracic transplantation than for kidney transplantation, the cultural and societal concerns are also evident in this setting.

Other subgroups, such as infants and highly sensitized individuals, also experience barriers to transplantation. Dedicated transplantation programmes, such as those that focus on identifying donor organs of appropriate size or on detecting appropriate donors using specific cross-matching methods, are needed ${ }^{101}$.

Finally, women are more likely to become a living donor than to receive a living organ donation ${ }^{102}$. Moreover, transplant recipients - irrespective of whether the organ is from a living or deceased donor - are predominantly male, especially for kidney transplants ${ }^{103}$. Although this inequality in access to transplantation might reflect a sex bias in the incidence of pathologies necessitating transplantation ${ }^{104}$, psychological and socio-economic factors also contribute to this disparity ${ }^{105}$, and could be prevented by addressing aspects of the transplantation system, such as inequalities in selection for waitlisting or unbalanced prioritization scores, that disadvantage women ${ }^{105}$.

\section{Opt-in versus opt-out and donor registration}

Considerable variation in legal frameworks for donation exists across the EU. Several EU and EU-associated countries, including Ireland, Germany, Denmark, Estonia and Switzerland, use opt-in legislation whereby consent for donation needs to be specifically sought from the donors and/or their families. Other countries apply an opt-out system (that is, consent for donation is presumed, unless the potential donors have officially registered their refusal). The Netherlands has in the past few years transitioned to an opt-out system, whereas the German government was unsuccessful in making this step. Most European countries that use an opt-out system apply a 'soft approach', allowing for objections by family members but supported by moral and legal leverage provided by the policy acceptance of the opt-out approach.

Compared with opt-in systems, opt-out systems are associated with higher donor rates ranging from $23.3 \%$ to $61.5 \%$ according to some studies ${ }^{106,107}$. However, a 2019 study of 35 countries found no difference in transplantation rates between opt-out and opt-in systems ${ }^{108}$. Multivariate analyses performed as part of that study showed that opt-out systems were independently predictive of lower rates of living donation. The divergent findings of studies that have compared opt-in and opt-out policies may be attributable to residual confounding resulting from differences in definitions, the selection of countries analysed, the period of analysis, or the choice of adjustment factors. Although there seems to be a gradual shift towards the use of opt-out systems, available data suggest that this approach as such is not sufficient to increase transplantation rates, and thus the adoption of opt-out legislation should be accompanied by other measures ${ }^{109}$, such as all those outlined in this Roadmap. In addition, simplified donor registration procedures such as those applied in Italy (Supplementary Box 4) offer an approach to encouraging donation without imposing judicial pressure ${ }^{110}$. 


\section{Financial and infrastructural barriers}

Clinical activity related to transplantation should be subject to fair remuneration. Insufficient reimbursement to hospitals for deceased donation and organ retrieval is a major issue in some countries and may adversely affect donation rates. In many countries, the reimbursement for different kidney replacement therapies is disproportionate, such that dialysis is financially more rewarding than transplantation for care providers.

In the USA, for example, patients who receive dialysis at units managed by for-profit organizations have a lower chance of undergoing transplantation than patients treated at not-for-profit units ${ }^{111,112}$. Although difficult to extrapolate these findings to the EU, this suggests that the current imbalance in financial yield between different kidney replacement therapies can jeopardize transplantation rates, but also that differences in economic models governing health care should be considered by health-care administrations to incentivize transplantation over other approaches. For example, additional reimbursement could be given to units that have achieved high rates of transplantation among their population of patients with end-stage organ failure (Supplementary Box 5).

Furthermore, expansion of transplantation programmes should be supported by investment in adequate infrastructure. Recommendations for optimal infrastructure requirements and staffing of transplantation and intensive care units - including optimal numbers of surgeons, operating theatres, intensive care facilities, appropriate hospitalization and outpatient follow-up facilities, and well-trained nursing and medical staff - are all urgently needed.

\section{Long-term preservation of graft function}

Long-term preservation of graft function is the most important outcome for transplant recipients ${ }^{43}$. Maintenance of graft function entails avoidance of damage by rejection, medication, complications, comorbidities, or damage to other organs (for example, avoiding kidney damage in heart or liver transplant recipients due to immunosuppressive medication), but also requires specific attention to fatal outcomes or complications that might jeopardize future transplantation procedures (such as opportunistic infections, malignancy, cardiovascular disease, post-transplantation diabetes mellitus $)^{50,113}$. In the first 10 years after transplantation mortality is substantially higher than that of the general population, at around $40 \%{ }^{114}$, with a similar percentage of fatalities over the subsequent 10 years ${ }^{50,115}$. In addition, at least $15 \%$ of survivors lose function of the transplanted organ per decade ${ }^{116}$. Of note, despite a consistent improvement in kidney graft survival in the first 5 years post-transplant between 1986 and 2015, graft survival after the fifth year of transplantation has not substantially changed over time ${ }^{116}$.

Several aspects of the transplantation process should be addressed to maximize the likelihood of transplant survival. Cold ischaemia time is an important modifiable risk factor for poor transplant outcomes ${ }^{117-119}$, and it is imperative that transplantation logistics are constantly reviewed and improved to keep cold ischaemia time as

\section{Box 1 | Non-medical barriers to transplantation}

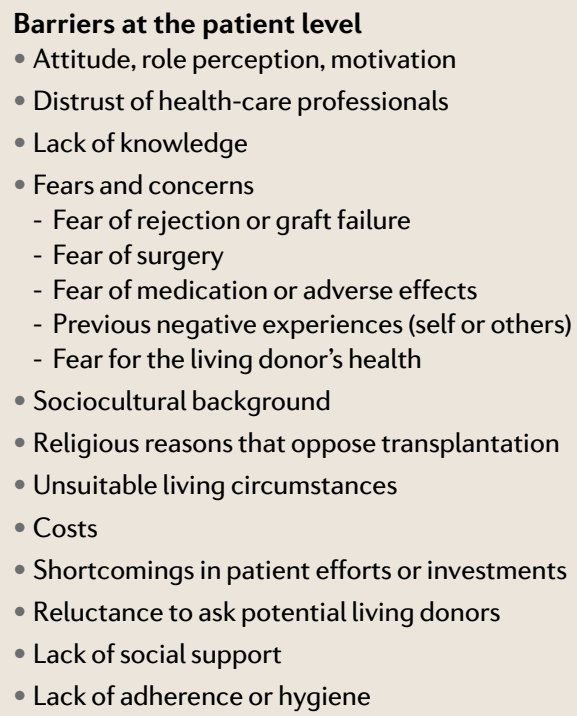

Barriers at the level of the health-care professional

- Attitude, role perception, motivation

- Lack of knowledge and expertise

- Fears and concerns

- Difficulty in selecting patients

- Lack of communication skills

Barriers at the level of the health-care system

- Financial barriers

- Lack of support staff

- Competition with other treatment modalities

- Patient doing well on other treatment modalities

Adapted with permission from REFS ${ }^{2,136}$, the European Kidney Health Alliance.

short as possible. Controlling organ fibrosis may be one of the few solutions to preventing long-term graft loss, but therapeutic solutions to tackle this problem are scarce $^{120}$. For recipients of kidney transplants experiencing graft loss, timely and uncomplicated transition onto dialysis is essential, as mortality is high in the period of dialysis (re-)initiation ${ }^{121}$. Non-adherence to medication is a major contributor to graft loss ${ }^{122,123}$ and interventions that augment adherence increase graft survival ${ }^{124}$. Monitoring markers of immunosuppression can also help to individualize immunosuppressive therapy to maximize drug efficacy and minimize toxicity ${ }^{125,126}$.

A critical consideration for paediatric transplant recipients is their transition to adult transplantation clinics. This transition period can be associated with reduced compliance related to the change in environment, as differences in the approach and philosophy of adult transplantation clinics may be perceived as inhospitable by adolescents who are often psychologically and socially vulnerable ${ }^{127}$.

A significant number of graft-survival years are lost when young donor kidneys are transplanted into older recipients and vice versa ${ }^{128}$. Matching the life expectancy of the intended recipient with the projected life span of 
the transplant is likely to maximize graft survival and cost savings ${ }^{128}$. Complex algorithms are required to ensure optimal matching and account for differences in population demographics. Other factors that affect long-term organ function, such as the presence of low-level preformed donor-specific HLA antibodies require further study ${ }^{129}$. The role of lifestyle factors and the possible role of tailored medication also deserve further consideration.

\section{Clustering of countries}

Some countries have a strong track record in living donation and others in deceased donation, but few do both well. Similarly, some may be more successful than others at transplanting specific organs. Several countries could benefit from improving their donor coordination and recruitment processes and/or from adopting or improving expanded donation criteria. Specific scenarios should be developed according to the areas that require improvement, with countries grouped according to these characteristics. Even countries that perform well overall have room for further improvement, as exemplified by Spain, which manages to improve every year upon already high transplantation rates (Supplementary Figure 1).

Clustering of countries with similar needs and characteristics can streamline the development of action plans that enable different strategies for each cluster. These action plans should also account for countryspecific measures and include in-depth consultation with the local transplant communities, including National Competent Authorities, transplant physicians, coordinators, regulators and authorities with representatives of other countries and the EU, enabling rapid dissemination and implementation of good clinical practice. This clustering approach could group countries with specific characteristics, for example, those needing to increase living donation compared with rates of deceased donation, or those where expanded donation criteria or donation overall could be enhanced.

\section{Benchmarking}

The optimization of transplantation programmes necessitates continuous assessment with external audits and comparison of their efficiency with peer programmes ${ }^{130}$. A uniform registration process and quality control system for organ donation and transplantation throughout Europe is necessary to enable this benchmarking. Transparency of hospitals in reporting their performance for access to and outcomes of transplantation is essential ${ }^{112}$. It is imperative that pan-European transplant registries are established for each organ, to enable benchmarking and ensure that comparable results are achieved across the EU. These comparisons would inform the specific areas for development and address local factors to ensure equitable access to transplantation and to optimize outcomes across Europe. Initiatives that enable comparisons of organ donation and transplantation rates between countries, similar to that developed by the Council of Europe Committee on Organ Transplantation, can help to stimulate countries that are seeking to achieve best practices ${ }^{131}$. Studying the approaches of the best performers will identify a number of critical factors for success, which can then be implemented elsewhere ${ }^{132}$.

Specific frameworks that promote and guide appropriate evidence-based decision making in the context of transplantation should be facilitated and supported. Recommendations might include but should not be limited to criteria for acceptance of patients on the waiting list; adequate follow-up post-transplantation; criteria for DCD transplantation; standards for transplant centres to achieve a well-functioning programme supported by adequate infrastructure; and optimal conditions for donor organ recovery. The application of European recommendations should be based on a continuously audited pan-European platform but allow adaptations according to the situation of individual countries. In Spain, benchmarking of different elements of the transplantation process is one of the cornerstones of its success ${ }^{39}$.

\section{Research}

Despite substantial national and trans-national progress over the past five decades, several fundamental questions in the field of transplantation remain unsolved. These range from the basic patho-physiology, immunology and molecular biology of the transplantation process and the response of the host to the donor organ, to clinical aspects and those relating to organizational, societal, psychological and quality of life issues. Transplantation research deserves specific attention for funding and support. Patients, medical professionals and society as a whole will benefit from research streamlined to focus on a number of areas and topics of prime interest (BOX 2), with the aim of better shaping future priorities, developments and policy actions in the field.

\section{International organ exchange}

Several EU countries do not have an efficient system to enable the internal offering and sharing of donated organs, nor do they collaborate in wider, usually transnational programmes for deceased donor organ exchange (such as Eurotransplant, Scandiatransplant or the South Alliance for Transplantation). At a minimum, each country should have a national sharing scheme between the local transplant centres whereby an optimal match between donor and recipient and rapid organ removal and transfer to the receiving centre are assured. Furthermore, gradual incorporation into one of the existing international exchange systems should be encouraged as an approach to boost transplantation activity ${ }^{42}$, as exemplified by Croatia in the early 2000s, or more recently by Hungary ${ }^{133}$. Such programmes enable expansion of the donor pool and provide a transparent, equitable and defensible method with which to match the most appropriate donor-recipient pairs as rapidly as possible and thereby improve donor outcomes. In Switzerland, which in essence operates an individual national procurement and offering system (Swisstransplant), close to $6 \%$ of the heart transplants and $3 \%$ of the lung transplants originate from cross-border organ sharing ${ }^{134}$.

In 2012 the FOEDUS-EOEO platform was launched. FOEDUS-EOEO is an IT-based system that allows European countries to connect with allocation offices 


\section{Box 2 | Suggested research topics}

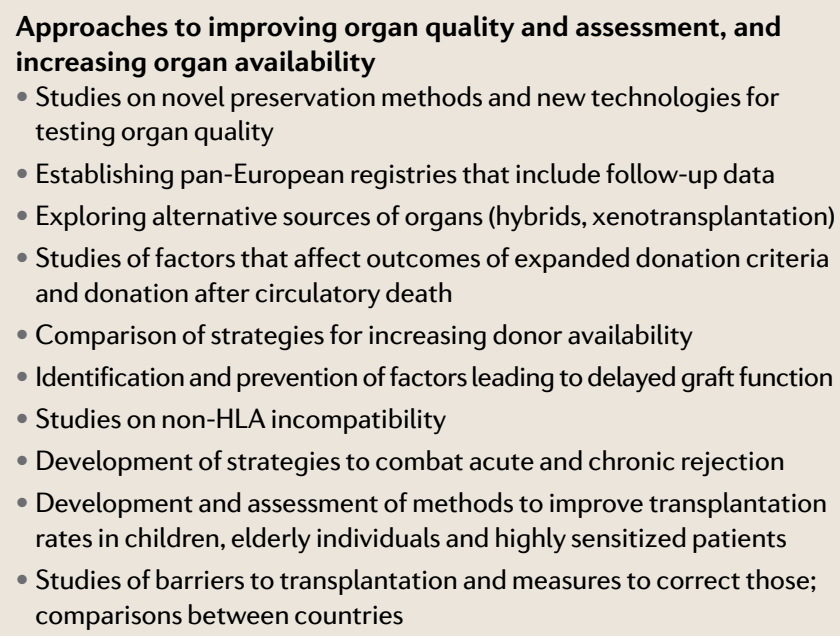

Socio-economic and societal impact of transplantation

- Health-economic comparison of transplantation programmes in different EU countries

- Identification of approaches to decrease the societal cost of transplantation

- Studies of the ecological footprint of kidney transplantation compared with dialysis

- Studies of factors preventing reemployment after transplantation

Extending the life of the transplant and reducing graft loss

- Defining surrogate end points for post-transplantation outcomes
- Identification of biomarkers of acute and chronic rejection, graft failure and negative outcomes at large

- Detection of mechanisms causing graft dysfunction via development of fibrosis and ways of preventing this evolution

- Prevention of post-transplantation malignancy and cardiovascular disease

- Prevention and adequate treatment of infections after transplantation

- Strategies to improve outcomes for patients with a failing kidney transplant who are transitioning to dialysis

Benchmarking, professionalism and governance

- Comparisons of different types of machine perfusion related to different organs for preservation, especially donation after circulatory death

- Certification of skills of professionals and professional regulation

- Benchmarking of transplantation outcomes (based on registry data)

- Study of barriers to transplantation in different countries

Patient priorities

- Studies on patient-reported outcomes

- Studies of mechanisms that determine treatment choice (transplantation compared with alternatives such as dialysis) and suggestions as to how valid patients can be encouraged to undergo transplantation

- Comparative studies of educational programmes (for the general population, patients, students, professionals) and development of best practices

Adapted with permission from REF.136, the European Kidney Health Alliance. ensuring that the organs that cannot be matched within the national or collaborative supra-national systems are available internationally. This type of broad international collaboration is especially beneficial for children and adolescents ${ }^{11}$ but also for other vulnerable recipients within a small donor pool (for example, highly sensitized patients).

\section{Conclusions}

Despite a good overall track record in the field of transplantation, disparities in transplantation rates between EU countries suggest that there remains ample room for improvement. The Action Plan launched by the EU in 2009 increased organ donation and transplantation and was in place until 2015, but further action is now needed to boost activity. Given the substantial differences between countries in transplantation practices (for example, in the overall transplantation rate, ratio of deceased compared with living donation, application of expanded donation and transplantation of specific organs), an in-depth analysis of discrepancies in transplantation rates is required to inform future improvements across the EU. Optimization and coordination of the donation process is indispensable for a successful transplantation programme. Education of patients, professionals and the general population as well as the provision of appropriate legal and financial frameworks is also necessary. This Roadmap, formulated from a thematic network of European organizations, gives a number of recommendations ${ }^{3}$ that provide a framework for further action with which to better cope with the growing transplant waiting lists, reduce the number of patients dying on waiting lists, improve equality in access to transplantation, and improve the outcomes of transplanted organs, inside, as well as outside, the EU.

In this Roadmap, we assume that the primary element needed to increase the number of patients with a functioning graft is increased organ donation, which requires investment in processes to coordinate the donation process, approaches to encouraging living donation and consideration of expanded donation criteria. However, donation cannot be enhanced without a parallel investment in infrastructure, the implementation of approaches to overcoming financial barriers, and educational efforts. The remaining factors, such as the need for benchmarking, registration, research and efforts to abolish inequities, might not directly affect the total number of transplants, but their consideration remains essential for ethical reasons and because they support the other strategies. The Joint Statement on which this Roadmap is based ${ }^{3}$ outlines a number of key areas along which policy makers could streamline such a plan (Supplementary Box 6). The development of such a plan should aim to stimulate increases in transplantation rates similar to those achieved following implementation of the original EU Action Plan on Organ Donation and Transplantation (2009-2015), and should involve yearly assessments and adjustments per country or group of countries, with successful countries serving as examples for the others.

Published online 5 May 2021 
1. Vanholder, R. et al. Reducing the costs of chronic kidney disease while delivering quality health care: a call to action. Nat. Rev. Nephrol. 13, 393-409 (2017).

2. Vanholder, R. et al. How to increase kidney transplant activity throughout Europe - an advocacy review by the European Kidney Health Alliance. Nephrol. Dial. Transplant. 34, 1254-1261 (2019).

3. European Kidney Health Alliance. Joint Statement Thematic Network on Improving Organ Donation and Transplantation in the EU 2019 http://ekha.eu/ wp-content/uploads/FINAL Joint-Statement-ofthe-Thematic-Network-on-Organ-Donation-andTransplantation.pdf (2019)

4. World Health Organization. Noncommunicable diseases. WHO http://www euro who int/en/healthtopics/noncommunicable-diseases/noncommunicablediseases (2017).

5. NCD Countdown Collaborators. NCD Countdown 2030: worldwide trends in non-communicable disease mortality and progress towards Sustainable Development Goal target 3.4. Lancet 392 1072-1088 (2018).

6. Delmonico, F. L., Dominguez-Gil, B., Matesanz, R. $\&$ Noel, L. A call for government accountability to achieve national self-sufficiency in organ donation and transplantation. Lancet 378, 1414-1418 (2011).

7. WHO, Transplantation Society, Organization Nacional de Transplantes. Third WHO Global Consultation on Organ Donation and Transplantation: striving to achieve self-sufficiency, March 23-25, 2010, Madrid, Spain. Transplantation 91 (Suppl. 11), S27-S28 (2011).

8. Dominguez-Gil, B. International figures on donation and transplantation 2019. Newsletter Transplant. European Parliament https://www.europarl.europa.eu/ EPRS/Newsletter Transplant 2019.pdf (2020).

9. Haase, B. et al. Ethical, legal, and societal issues and recommendations for controlled and uncontrolled DCD. Transpl. Int. 29, 771-779 (2016).

10. Lomero, M. et al. Donation after circulatory death today: an updated overview of the European landscape. Transpl. Int. 33, 76-88 (2020).

11. Bouwman, R. et al. Study on the uptake and impact of the EU Action Plan on Organ Donation and Transplantation (2009-2015) in the EU Member States. European Commission https://ec.europa.eu/ health/sites/health/files/blood_tissues_organs/docs/ 2017_euactionplan_2009-2015_impact_exe_en.pdf (2017).

12. Zoccali, C., Kramer, A. \& Jager, K. The databases: renal replacement therapy since 1989 - the European Renal Association and European Dialysis and Transplant Association (ERA-EDTA). Clin. J. Am. Soc. Nephrol. 4 (Suppl. 1), 18-22 (2009).

13. No Authors Listed. Organ Transplant Scandal Shocks Germany. Spiegel http://www.spiegel.de/international/ germany/organ-transplant-scandal-shocks-germanya-848016.html (2012).

14. Foreman, K. J. et al. Forecasting life expectancy, years of life lost, and all-cause and cause-specific mortality for 250 causes of death: reference and alternative scenarios for 2016-40 for 195 countries and territories. Lancet. 392, 2052-2090 (2018).

15. Tonelli, M. et al. Systematic review: kidney transplantation compared with dialysis in clinically relevant outcomes. Am. J. Transplant. 11, 2093-2109 (2011)

16. Haller, M. C., Kainz, A., Baer, H. \& Oberbauer, R. Dialysis vintage and outcomes after kidney transplantation: a retrospective cohort study. Clin. J. Am. Soc. Nephrol. 12, 122-130 (2017).

17. Wong, G. et al. Comparative survival and economic benefits of deceased donor kidney transplantation and dialysis in people with varying ages and co-morbidities. PLOS ONE 7, e29591 (2012)

18. European Renal Association - European Dialysis and Transplant Association. ERA-EDTA Registry: ERA-EDTA Registry Annual Report 2017. ERA-EDTA https://eraedta-reg.org/files/annualreports/AnnRep2017.pdf (2017).

19. Cassuto, J. R. et al. Wait list death and survival benefit of kidney transplantation among nonrenal transplant recipients. Am. J. Transplant. 10, 2502-2511 (2010).

20. Haller, M., Gutjahr, G., Kramar, R., Harnoncourt, F. \& Oberbauer, R. Cost-effectiveness analysis of renal replacement therapy in Austria. Nephrol. Dial. Transplant. 26, 2988-2995 (2011).

21. Mohnen, S. M. et al. Healthcare costs of patients on different renal replacement modalities - Analysis of Dutch health insurance claims data. PLOS ONE 14, e0220800 (2019).
22. Bhutiani, N. et al. A cost analysis of early biliary strictures following orthotopic liver transplantation in the United States. Clin. Transplant. 32, e13396 (2018).

23. Dageforde, L. A., Feurer, I. D., Pinson, C. W. \& Moore, D. E. Is liver transplantation using organs donated after cardiac death cost-effective or does it decrease waitlist death by increasing recipient death? HPB 15, 182-189 (2013)

24. Williams, R. et al. Disease burden and costs from excess alcohol consumption, obesity, and viral hepatitis: fourth report of the Lancet Standing Commission on Liver Disease in the UK. Lancet 391 , 1097-1107 (2018)

25. Long, E. F., Swain, G. W. \& Mangi, A. A. Comparative survival and cost-effectiveness of advanced therapies for end-stage heart failure. Circ. Heart Fail. 7 , 470-478 (2014)

26. Ye, X. T., Parker, A., Brink, J., Weintraub, R. G. \& Konstantinov, I. E. Cost-effectiveness of the National Pediatric Heart Transplantation Program in Australia. J. Thorac. Cardiovasc. Surg 157, 1158-1166 (2018).

27. OECD \& European Union. Health at a Glance: Europe 2016 - State of Health in the EU Cycle. OECD iLibrary https://doi.org/10.1787/9789264265592-en (2016).

28. Danuser, B. et al. Employment 12 months after kidney transplantation: An in-depth bio-psycho-social analysis of the Swiss Transplant Cohort. PLOS ONE 12, e0175161 (2017).

29. Dukic, M. Z. \& Zibar, L. Employment in patients with renal replacement therapy. SEEMED J. 3, 11-20 (2019).

30. Julian Mauro, J. C., Molinuevo Tobalina, J. A. \& Sanchez Gonzalez, J. C. Employment in the patient with chronic kidney disease related to renal replacement therapy. Nefrologia. 32, 439-445 (2012).

31. Liem, Y. S., Bosch, J. L. \& Hunink, M. G. Preferencebased quality of life of patients on renal replacement therapy: a systematic review and meta-analysis. Value Health 11, 733-741 (2008).

32. Manificat, S. et al. Quality of life of children and adolescents after kidney or liver transplantation: child, parents and caregiver's point of view. Pediatr. Transplant. 7, 228-235 (2003).

33. Commission of the European Communities. Action plan on Organ Donation and Transplantation (2009 2015): Strengthened Cooperation between Member. States. European Commission https://ec.europa.eu/ health/ph_threats/human_substance/oc_organs/docs/ organs action en.pdf (2008)

34. Wu, D. A. et al. Barriers to living donor kidney transplantation in the United Kingdom: a national observational study. Nephrol. Dial. Transplant. 32, 890-900 (2017)

35. Council of Europe. Legal Framework. https://www. edam.eu/en/legal-framework (2021).

36. No Authors Listed. The Madrid resolution on organ donation and transplantation: national responsibility in meeting the needs of patients, guided by the WHO principles. Transplantation 91 (Suppl. 11), S29-S31 (2011).

37. Hanson, C. S. et al. Nephrologists' perspectives on recipient eligibility and access to living kidney donor transplant. Transplantation 100, 943-953 (2016).

38. de Jong, R. W. et al. Non-medical barriers reported by nephrologists when providing renal replacement therapy or comprehensive conservative management to end-stage kidney disease patients: a systematic review. Nephrol. Dial. Transplant. https://doi.org/ 10.1093/ndt/gfz271 (2020).

39. Matesanz, R., Dominguez-Gil, B., Coll, E., de la Rosa, C. \& Marazuela, R. Spanish experience as a leading country: what kind of measures were taken? Transplant. Int. 24, 333-343 (2011).

40. Matesanz, R., Marazuela, R., Coll, E., Mahillo, B. $\&$ Dominguez-Gil, B. About the opt-out system, live transplantation, and information to the public on organ donation in Spain... Y ole! Am. J. Transpl. 17, 1695-1696 (2017).

41. Dominguez-Gil, B. End-of-life practices in patients with devastating brain injury in Spain: implications for organ donation. Med. Intensiva 41, 162-173 (2017).

42. Zivcic-Cosic, S. et al. Development of the Croatian model of organ donation and transplantation. Croat. Med. J. 54, 65-70 (2013).

43. European Kidney Health Alliance. European Kidney Forum 2019 "Organ Donation and Transplantation in Europe - Are We Meeting the Needs of Patients?" EKHA http://ekha.eu/blog/european-kidney-forum2019-organ-donation-and-transplantation-ineurope-are-we-meeting-the-needs-of-patients/ (2019).
44. Sautenet, B. et al. Developing consensus-based priority outcome domains for trials in kidney transplantation: a multinational Delphi survey with patients, caregivers, and health professionals. Transplantation 101, 1875-1886 (2017).

45. Dominguez-Gil, B., Murphy, P. \& Procaccio, F. Ten changes that could improve organ donation in the intensive care unit. Intensive Care Med. 42, 264-267 (2016).

46. Martin-Delgado, M. C. et al. Summary of Spanish recommendations on intensive care to facilitate organ donation. Am. J. Transplant. 19, 1782-1791 (2019).

47. Shrestha, S. et al. Logistical factors influencing cold ischemia times in deceased donor kidney transplants. Transplantation 100, 422-428 (2016).

48. Miller, C. \& Breakwell, R. What factors influence a family's decision to agree to organ donation? A critical literature review. London J. Prim. Care 10, 103-107 (2018).

49. Dominguez-Gil, B. et al. The critical pathway for deceased donation: reportable uniformity in the approach to deceased donation. Transplant. Int. $\mathbf{2 4}$ 373-378 (2011)

50. Traynor, C. et al. Twenty-year survivors of kidney transplantation. Am. J. Transplant. 12, 3289-3295 (2012).

51. Reichman, T. W. et al. Living donor versus deceased donor liver transplantation: a surgeon-matched comparison of recipient morbidity and outcomes. Transpl. Int. 26, 780-787 (2013).

52. Mandelbrot, D. A. \& Pavlakis, M. Living donor practices in the United States. Adv. Chron. Kidney Dis. 19, 212-219 (2012)

53. Holscher, C. M. et al. Self-reported incident hypertension and long-term kidney function in living kidney donors compared with healthy nondonors. Clin. J. Am. Soc. Nephrol. 14, 1493-1499 (2019).

54. Kestenbaum, B. R. \& Seliger, S. L. Commentary on risks of living kidney donation: current state of knowledge on core outcomes important to donors. Clin. J. Am. Soc. Nephrol. 14, 609-610 (2019).

55. Lennerling, A. et al. Living organ donation practices in Europe - results from an online survey. Transpl. Int 26, 145-153 (2013)

56. Lentine, K. L., Lam, N. N. \& Segev, D. L. Risks of living kidney donation: current state of knowledge on outcomes important to donors. Clin. J. Am. Soc Nephrol. 14, 597-608 (2019).

57. Ferrari, P., Weimar, W., Johnson, R. J., Lim, W. H. \& Tinckam, K. J. Kidney paired donation: principles, protocols and programs. Nephrol. Dial. Transplant. 30, 1276-1285 (2015).

58. Biro, P. et al. Building kidney exchange programmes in europe-an overview of exchange practice and activities. Transplantation 103, 1514-1522 (2019).

59. Valentin, M. O. et al. International cooperation for kidney exchange success. Transplantation 103, e180-e181 (2019).

60. Bohmig, G. A. et al. Czech-Austrian kidney paired donation: first European cross-border living donor kidney exchange. Transplant. Int. 30, 638-639 (2017).

61. Working Group on Living Donation. Toolbox Living Kidney Donation. European Commission https://ec europa.eu/health/sites/health/files/blood tissues organs/docs/eutoolbox_living_kidney_donation_en.pdf (2016).

62. Truog, R. D. The ethics of organ donation by living donors. N. Engl. J. Med. 353, 444-446 (2005).

63. Port, F. K. et al. Donor characteristics associated with reduced graft survival: an approach to expanding the pool of kidney donors. Transplantation 74 1281-1286 (2002).

64. Watson, C. J., Johnson, R. J., Birch, R., Collett, D. $\&$ Bradley, J. A. A simplified donor risk index for predicting outcome after deceased donor kidney transplantation. Transplantation 93, 314-318 (2012).

65. Collett, D., Friend, P. J. \& Watson, C. J. Factors associated with short- and long-term liver graft survival in the United Kingdom: development of a UK donor liver index. Transplantation 101, 786-792 (2017).

66. Dahmen, M. et al. Validation of the Kidney Donor Profile Index (KDPI) to assess a deceased donor's kidneys' outcome in a European cohort. Sci. Rep. 9 11234 (2019).

67. Cohen, J. B. et al. Survival benefit of transplantation with a deceased diabetic donot kidney compared with remaining on the waitlist. Clin. J. Am. Soc. Nephrol. 12, 974-982 (2017). 
68. Ibrahim, M. et al. Utilization and outcomes of single and dual kidney transplants from older deceased donors in the United Kingdom. Clin. J. Am. Soc Nephrol. 15, 1320-1329 (2020)

69. Schaapherder, A. et al. Equivalent long-term transplantation outcomes for kidneys donated after brain death and cardiac death: conclusions from a nationwide evaluation. EClinicalMedicine 4, 25-31 (2018).

70. Summers, D. M. et al. Analysis of factors that affect outcome after transplantation of kidneys donated after cardiac death in the UK: a cohort study. Lancet 376, 1303-1311 (2010).

71. Smith, M., Dominguez-Gil, B., Greer, D. M., Manara, A. R. \& Souter, M. J. Organ donation after circulatory death: current status and future potential. Intensive Care Med. 45, 310-321 (2019).

72. Minambres, E., Rubio, J. J., Coll, E. \& Dominguez-Gil, B. Donation after circulatory death and its expansion in Spain. Curr. Opin. Organ. Transplant. 23, 120-129 (2018)

73. Trapero-Marugan, M., Little, E. C. \& Berenguer, M. Stretching the boundaries for liver transplant in the 21 st century. Lancet Gastroenterol. Hepatol. 3 803-811 (2018)

74. No Authors Listed. NEW release: 7th edition Guide to the quality and safety of Organs for transplantation. Council of Europe https://www.edam.eu/en/news/newrelease-7th-edition-guide-quality-and-safety-organstransplantation (2018)

75. Kumar, R. N. \& Stosor, V. Organ transplantation in persons with HIV. AIDS 34, 1107-1116 (2020).

76. Potluri, V. S. et al. National trends in utilization and 1 -year outcomes with transplantation of HCV-viremic kidneys. J. Am. Soc. Nephrol. 30, 1939-1951 (2019)

77. Givertz, M. M., Woolley, A. E. \& Baden, L. R. Expanding the donor pool with use of hepatitis $C$ infected hearts. Circ. Heart Fail. 11, e005656 (2018).

78. Ysebaert, D. et al. Organ procurement after euthanasia: Belgian experience. Transplant. Proc. 41, 585-586 (2009)

79. Wilkinson, D. ¿ Savulescu, J. Should we allow organ donation euthanasia? Alternatives for maximizing the number and quality of organs for transplantation. Bioethics 26, 32-48 (2012).

80. Bouwman, R., Wiegers, T van Schoten, S., Coppen, R. $\&$ Friele, R. Study on the uptake and impact of the EU Action Plan on Organ Donation and Transplantation (2009-2015) in the EU Member States. European Commission https://ec.europa.eu/health/sites/health/ files/blood tissues_organs/docs/2017 euactionplan 2009-2015_impact_exe_en.pdf (2017).

81. Dominguez-Gil, B. et al. Current situation of donation after circulatory death in European countries. Transplant. Int. 24, 676-686 (2011).

82. Mohan, S. et al. Factors leading to the discard of deceased donor kidneys in the United States. Kidney Int. 94, 187-198 (2018).

83. Stallone, G. \& Grandaliano, G. To discard or not to discard: transplantation and the art of scoring. Clin. Kidney J. 12, 564-568 (2019).

84. Manara, A., Procaccio, F. \& Dominguez-Gil, B. Expanding the pool of deceased organ donors: the ICU and beyond. Intensive Care Med. 45, 357-360 (2019).

85. Scandroglio, B. et al. Analysis of the attitudes and motivations of the Spanish population towards organ donation after death. Transpl. Int. 24, 158-166 (2011)

86. Byrne, $M$ et al School education to increase organ donation and awareness of issues in transplantation in the UK. Pediatr. Transplant. 23, e13492 (2019).

87. Febrero, B. et al. Knowledge of the brain death concept among older people. Transplant. Proc. 52, 506-508 (2020)

88. No Authors Listed. Gift of Life. European Kidney Health Alliance http://ekha.eu/gift-of-life/ (2018).

89. Zhang, X. et al. Racial/ethnic disparities in waitlisting for deceased donor kidney transplantation 1 year after implementation of the new national kidney allocation system. Am. J. Transplant. 18, 1936-1946 (2018)

90. Garg, A. X. Helping more patients receive a living donor kidney transplant. Clin. J. Am. Soc. Nephrol. 13, 1918-1923 (2018).

91. Hoogeveen, E. K. et al. Effect of obesity on the outcome of kidney transplantation: a 20-year follow-up. Transplantation 91, 869-874 (2011)

92. Oste, M. C. et al. Mediterranean style diet is associated with low risk of new-onset diabetes after renal transplantation. BMJ Open Diabetes Res. Care 5, e000283 (2017).

93. Van Biesen, W., van der Veer, S. N., Murphey, M., Loblova, O. \& Davies, S. Patients' perceptions of information and education for renal replacement therapy: an independent survey by the European Kidney Patients' Federation on information and support on renal replacement therapy. PLOS ONE 9, e 103914 (2014)

94. Norris, K. \& Nissenson, A. R. Race, gender, and socioeconomic disparities in CKD in the United States. J. Am. Soc. Nephrol. 19, 1261-1270 (2008).

95. Poulakou, G., Len, O. \& Akova, M. Immigrants as donors and transplant recipients: specific considerations. Intensive Care Med. 45, 401-403 (2019).

96. Ikram, U. Z., Kunst, A. E., Lamkaddem, M. \& Stronks, K. The disease burden across different ethnic groups in Amsterdam, the Netherlands, 2011-2030. Eur. J. Publ. Health 24, 600-605 (2013).

97. Zhang, Y., Gerdtham, U. G., Rydell, H. $\&$ Jarl, J. Socioeconomic inequalities in the kidney transplantation process: a registry-based study in Sweden. Transplant. Direct 4, e346 (2018).

98. Department of Health. Organs for Transplants A report from the Organ Donation Taskforce. NHS https://nhsbtdbe blob.core.windows.net/umbraco-assets-corp/4245/ organsfortransplantstheorgandonortaskforce 1 streport. pdf

99. Tiessen, J. et al. Improving Organ Donation and Transplantation in the European Union. Assessing the Impacts of European Action. Rand Europe https://www.rand.org/content/dam/rand/pubs/ technical_reports/2008/RAND_TR602.pdf (2008).

100. Bratton, C., Chavin, K. \& Baliga, P. Racial disparities in organ donation and why. Curr. Opin. Organ. Transpl. 16, 243-249 (2011).

101. Valentin, M. O. et al. Implementation of a nationa priority allocation system for hypersensitized patients in spain, based on virtual crossmatch: initial results. Transplant. Proc. 48, 2871-2875 (2016).

102. Puoti, F et al. Organ transplantation and gender differences: a paradigmatic example of intertwining between biological and sociocultural determinants. Biol. Sex. Differ. 7, 35 (2016).

103. Antlanger, M. et al. Sex differences in kidney replacement therapy initiation and maintenance. Clin. J. Am. Soc. Nephrol. 14, 1616-1625 (2019).

104. Carrero, J. J., Hecking, M., Chesnaye, N. C. \& Jager, K. J. Sex and gender disparities in the epidemiology and outcomes of chronic kidney disease. Nat. Rev. Nephrol. 14, 151-164 (2018).

105. Melk, A. et al. Equally interchangeable? How sex and gender affect transplant. Transplantation 103, 1094-1110 (2019)

106. Shepherd, L., O'Carroll, R. E. \& Ferguson, E. An international comparison of deceased and living organ donation/transplant rates in opt-in and opt-out systems: a panel study. BMC Med. 12, 131 (2014).

107. Abadie, A. \& Gay, S. The impact of presumed consent legislation on cadaveric organ donation: a crosscountry study. J. Health Econ. 25, 599-620 (2006).

108. Arshad, A., Anderson, B. \& Sharif, A. Comparison of organ donation and transplantation rates between opt-out and opt-in systems. Kidney Int. 95 1453-1460 (2019).

109. Matesanz, R \& Dominguez-Gil, B. Opt-out legislations: the mysterious viability of the false. Kidney Int. 95, 1301-1303 (2019)

110. Howard, K. et al. Preferences for policy options for deceased organ donation for transplantation: a discrete choice experiment. Transplantation 100, 1136-1148 (2016).

111. Gander, J. C. et al. Association between dialysis facility ownership and access to kidney transplantation. JAMA 322, 957-973 (2019).

112. Boulware, L. E., Wang, V. \& Powe, N. R. Improving access to kidney transplantation: business as usual or new ways of doing business? JAMA 322, 931-933 (2019).

113. Heemann, U., Abramowicz, D., Spasovski, G., Vanholder, R. \& European Renal Best Practice Work Group on Kidney Transplantation. Endorsement of the kidney disease improving global outcomes (KDIGO) guidelines on kidney transplantation: a European Renal Best Practice (ERBP) position statement. Nephrol. Dial. Transplant. 26, 2099-2106 (2011).

114. Pippias, M et al. The European Renal Association European Dialysis and Transplant Association Registry Annual Report 2014: a summary. Clin. Kidney J. 10, $154-169(2017)$
115. Khush, K. K. et al. The International Thoracic Organ Transplant Registry of the International Society for Heart and Lung Transplantation: thirty-fifth adult heart transplantation report-2018; focus theme: multiorgan transplantation. J. Heart Lung Transplant. 37, 1155-1168 (2018)

116. Coemans, M. et al. Analyses of the short- and longterm graft survival after kidney transplantation in Europe between 1986 and 2015. Kidney Int. 94 964-973 (2018).

117. Schroppel, B. \& Legendre, C. Delayed kidney graft function: from mechanism to translation. Kidney Int 86, 251-258 (2014)

118. Perico, N., Cattaneo, D., Sayegh, M. H. \& Remuzzi, G. Delayed graft function in kidney transplantation. Lancet 364, 1814-1827 (2004).

119. Debout, A. et al. Each additional hour of cold ischemia time significantly increases the risk of graft failure and mortality following renal transplantation. Kidney Int. 87, 343-349 (2015)

120. Breyer, M. D. \& Susztak, K. The next generation of therapeutics for chronic kidney disease. Nat. Rev. Drug Discov. 15, 568-588 (2016).

121. Gill, J. S., Rose, C., Pereira, B. J. \& Tonelli, M The importance of transitions between dialysis and transplantation in the care of end-stage renal disease patients. Kidney Int. 71, 442-447 (2007).

122. Prendergast, M. B. \& Gaston, R. S. Optimizing medication adherence: an ongoing opportunity to improve outcomes after kidney transplantation. Clin. J. Am. Soc. 5, 1305-1311 (2010).

123. Dobbels, F., Van Damme-Lombaert, R., Vanhaecke, J. $\&$ De Geest, S. Growing pains: non-adherence with the immunosuppressive regimen in adolescent transplant recipients. Pediatr. Transplant. 9 , 381-390 (2005)

124. Russell, C. L. et al. Improving medication adherence and outcomes in adult kidney transplant patients using a personal systems approach: SystemCHANGE results of the MAGIC randomized clinical trial. Am. J. Transplant. 20, 125-136 (2020).

125. Kuypers, D. R. Immunosuppressive drug monitoring what to use in clinical practice today to improve renal graft outcome. Transpl. Int. 18, 140-150 (2005).

126. Wieland, E. et al. Biomarkers as a tool for management of immunosuppression in transplant patients. Ther. Drug Monit. 32, 560-572 (2010).

127. Bell, L. E. et al. Adolescent transition to adult care in solid organ transplantation: a consensus conference report. Am. J. Transplant. 8, 2230-2242 (2008)

128. Meier-Kriesche, H. U., Schold, J. D., Gaston, R. S. Wadstrom, J. \& Kaplan, B. Kidneys from deceased donors: maximizing the value of a scarce resource. Am. J. Transplant. 5, 1725-1730 (2005).

129. Huang, E. \& Jordan, S. C. Clinical and public policy implications of pre-formed DSA and transplant outcomes. Clin. J. Am. Soc. Nephrol. 14, 972-974 (2019).

130. de la Rosa, G. et al. Continuously evaluating performance in deceased donation: the Spanish quality assurance program. Am. J. Transplant. 12 , 2507-2513 (2012).

131. Weiss, J. et al. Evolution of deceased organ donation activity versus efficiency over a 15-year period: an international comparison. Transplantation 102 , 1768-1778 (2018).

132. Matesanz, R. et al. Benchmarking in the process of donation after brain death: a methodology to identify best performer hospitals. Am. J. Transplant. 12, 2498-2506 (2012).

133. No Authors Listed. Eurotransplant region. Eurotransplant https://www.eurotransplant.org/ about-eurotransplant/region/ (2021).

134. Schneider, S., Schreiner, P., Weiss, J. \& Immer, F. F. Assessing the potential of international organ exchange-the Swiss experience. Eur. J. Cardiothorac Surg. 40, 1368-1373 (2011).

135. Organizacion Nacional De Trasplantes. Publicaciones ONT http://www.ont.es/publicaciones/Paginas/ Publicaciones.aspx (2021)

136. European Kidney Health Alliance. Thematic Network on Improving Organ Donation and Transplantation in the EU 2019. EKHA http://ekha eu/wp-content/ uploads/FINAL 14.01.2020 Joint-Statement-ofthe-Thematic-Network-on-Organ-Donation-andTransplantation.pdf (2020).

\section{Acknowledgements}

Each year the European Union commissions a number of Joint Statements regarding health issues, which bring together several stakeholder groups to make recommendations to the European Commission for the coming years. 
The coordination of the joint statement informing the present Roadmap was allocated to the European Kidney Health Alliance (EKHA). The EKHA represents a common effort by all European key stakeholders in kidney care (patients, nurses, physicians, foundations) to propose solutions for the challenges of kidney disease in Europe through the development of effective prevention and more efficient care pathways. In addition to the EKHA, the organizations involved in this publication and the European Commission Joint Statement ar either pan-European Organizations with a focus on transplan tation or transplantable organs or the National Transplant Organizations of Croatia and Spain. Specifically, these organizations are the European Society of Organ Transplantation (ESOT); the European Renal Association-European Dialysis and Transplant Association (ERA-EDTA); the ERA-EDTA Registry; United European Gastroenterology (UEG); the European Association for the Study of the Liver (EASL) and the National Competent Authorities for Organ Donation and Transplantation of Croatia and Spain. The Join Statement was endorsed by 54 Organizations and Institutions and by 19 Members of the European Parliament. The authors are indebted to Marine Faure and Sophie Bruno (Senior Consultants, Interel European Affairs) and Nazli Gül (Consultant, Interel European Affairs) for their assistance in the preparation of the Joint Statement that is the basis for this publication.

\section{Author contributions}

R.V. contributed to conceptualizing and designing the Roadmap, data analyses, the literature search and writing of the manuscript. B.D.-G. contributed to designing the Roadmap, performing the literature search, data collection and writing. G.C.O. contributed to designing the Roadmap performing the literature search, writing and editing the manuscript before submission. M.B., H.C.-P. and J.C.C. contributed to writing of the manuscript. K.J.J. contributed to writing and data collection. B.M. contributed to data collec tion. V.S.S. and M.O.V. contributed to the literature search, writing and data collection.

\section{Competing interests}

R.V. reports unrestricted grants to the European Kidney Health Alliance from Baxter Health Care, Astellas, Amgen, BBraun, CSL Behring, Hansa BioPharma and Viforpharma, for the organization of the annual EKHA Kidney Forum at the European Parliament. H.C.-P. reports personal fees from Intercept, Gilead, Promethera and Genfit, outside of the submitted work. K.J.J. reports grants from ERA-EDTA during the conduct of the study, and personal fees from Fresenius Medical Care, outside of the submitted work. The other authors declare no conflicts of interest.

Peer review information

Nature Reviews Nephrology thanks L. Hilbrands, who co-reviewed with M. Baas, A. Rahmel, and the other, anonymous, reviewer(s) for their contribution to the peer review of this work.

Publisher's note

Springer Nature remains neutral with regard to jurisdictional claims in published maps and institutional affiliations.

Supplementary information

The online version contains supplementary material available at https://doi.org/10.1038/s41581-021-00425-3.

\section{RELATED LINKS}

European Kidney Health Alliance: http://ekha.eu/

FOEDUS-EOEO: https://www.foedus-eoeo.eu/\#/public

C Springer Nature Limited 2021 